University of Nebraska - Lincoln

DigitalCommons@University of Nebraska - Lincoln

\title{
Prevalence of liver disease in veterans with bipolar disorder or schizophrenia
}

\author{
Bret E. Fuller \\ Portland Veterans Affairs Medical Center \\ Veronica L. Rodriguez \\ Portland Veterans Affairs Medical Center \\ Alex Linke \\ Portland Veterans Affairs Medical Center \\ Mirko Sikirica \\ Ortho-McNeil Janssen Scientific Affairs \\ Riad Dirani \\ Ortho-McNeil Janssen Scientific Affairs \\ See next page for additional authors
}

Follow this and additional works at: https://digitalcommons.unl.edu/publichealthresources

Part of the Public Health Commons

Fuller, Bret E.; Rodriguez, Veronica L.; Linke, Alex; Sikirica, Mirko; Dirani, Riad; and Hauser, Peter, "Prevalence of liver disease in veterans with bipolar disorder or schizophrenia" (2011). Public Health Resources. 172.

https://digitalcommons.unl.edu/publichealthresources/172

This Article is brought to you for free and open access by the Public Health Resources at DigitalCommons@University of Nebraska - Lincoln. It has been accepted for inclusion in Public Health Resources by an authorized administrator of DigitalCommons@University of Nebraska - Lincoln. 


\section{Authors}

Bret E. Fuller, Veronica L. Rodriguez, Alex Linke, Mirko Sikirica, Riad Dirani, and Peter Hauser 


\title{
Prevalence of liver disease in veterans with bipolar disorder

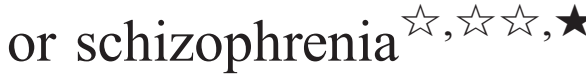

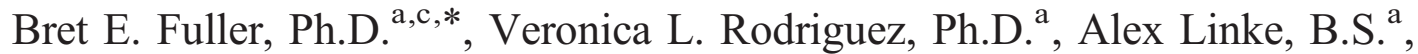 \\ Mirko Sikirica, Pharm.D. ${ }^{\mathrm{b}}$, Riad Dirani, Ph.D. ${ }^{\mathrm{b}}$, Peter Hauser, M.D. ${ }^{\mathrm{d}}$ \\ ${ }^{a}$ Portland Veterans Affairs Medical Center, Portland, OR, USA \\ ${ }^{\mathrm{b}}$ Ortho-McNeil Janssen Scientific Affairs, LLC, Titusville, NJ, USA \\ 'Oregon Health and Science University, Department of Public Health and Preventive Medicine, Portland, OR, USA \\ ${ }^{\mathrm{d}}$ Veterans Integrated Service Network 22 Network Office, Long Beach Veterans Affairs Medical Center, Long Beach, CA, USA
}

Received 12 November 2010; accepted 10 March 2011

\begin{abstract}
Objective: To assess the prevalence of three liver diseases [hepatitis $\mathrm{C}$ virus (HCV), nonalcoholic fatty liver disease and alcohol-induced cirrhosis] in patients (veterans) with/without schizophrenia/schizoaffective disorder and bipolar disorder.

Methods: A retrospective electronic chart review of Veterans Integrated Services Network 20 facilities from January 1, 2001 to December 21, 2006 selected patients to one of two groups: schizophrenia/schizoaffective disorder or bipolar disorder. Patients in both groups were compared with veterans in an equal-sized random sample from the same data set of veterans without psychiatric diagnoses. Logistic regression models evaluated risk for overall liver diseases as well as $\mathrm{HCV}$, nonalcoholic fatty liver disease and alcoholic-induced cirrhosis. Results: Patients with schizophrenia $(n=6521)$ had a higher prevalence of liver disease [22.4\% versus 3.2\%; odds ratio (OR)=8.73]; HCV $(16.5 \%$ versus $1.9 \%$; $\mathrm{OR}=10.21)$; and alcohol-related cirrhosis $(1.6 \%$ versus $0.4 \%$; OR=4.09) than matched controls. Patients with bipolar disorder $(n=5319)$ had a higher prevalence of liver disease $(21.5 \%$ versus $3.5 \%$; OR=7.58); HCV $(15.5 \%$ versus $2.1 \%$; OR=8.60); and alcohol-related cirrhosis $(1.6 \%$ versus $0.4 \%$; OR=3.82) than matched controls. Risk factors for liver disease in patients with schizophrenia (versus matched controls) included diabetes $(\mathrm{OR}=1.29)$, hypertension $(\mathrm{OR}=1.27), \mathrm{HIV}(\mathrm{OR}=3.54)$, substance use disorder $(\mathrm{SUD})(\mathrm{OR}=2.28)$, alcohol use disorder $(\mathrm{OR}=3.05)$ and schizophrenia $(\mathrm{OR}=2.74)$. Risk factors for development of liver disease for patients with bipolar disorder: diabetes $(\mathrm{OR}=1.40)$, $\mathrm{HIV}(\mathrm{OR}=3.66)$, $\mathrm{SUD}(\mathrm{OR}=2.68)$, alcohol use disorder $(\mathrm{OR}=3.22)$ and bipolar disorder $(\mathrm{OR}=2.27)$.

Conclusions: This study in veterans shows that the presence of mental illness and its comorbidities represents a significant risk factor for the diagnosis of liver disease, including HCV and alcohol-related cirrhosis.
\end{abstract}

Published by Elsevier Inc.

Keywords: Liver disease; Veterans; Bipolar disorder; Schizophrenia

\footnotetext{
th Disclosure of Interests: Drs. Fuller and Rodriguez and Mr. Linke have no commercial or financial interests to report. Dr. Hauser is a member of the speaker's bureau for AstraZeneca and Merck and received funding from Ortho-McNeil Janssen for this study. Drs. Dirani and Sikirica are employees of Ortho-McNeil Janssen Scientific Affairs, LLC, and Johnson \& Johnson stockholders.

站放 This study was funded by a grant from Ortho-McNeil Janssen Scientific Affairs.

$\star$ This study was presented at the 162nd Annual American Psychiatric Association Meeting, May 20, 2009, San Francisco, CA, USA.

* Corresponding author. Portland Veterans Affairs Medical Center, 3170 SW US Veterans Park Road, Mailcode: P3MHDC, Portland, OR 97210, USA. Tel.: +1 503220 8262x54469; fax: +1 5032203499.

E-mail address: bret.fuller@va.gov (B.E. Fuller).
}

\section{Introduction}

Epidemiologic studies show that, among Axis I diagnoses, bipolar disorder and schizophrenia have been associated with the highest risk for comorbid substance use disorders (SUDs) [1-5]. Selected studies found that among individuals with serious mental illness (SMI) - primarily schizophrenia or schizoaffective disorder diagnoses- $45.9 \%$ had SUDs, $20.1 \%$ had injected drugs and $14.5 \%$ had shared needles $[4,5]$. Other studies suggest that over $50 \%$ of patients with bipolar disorder have a past or present SUD. This SUD comorbidity is associated with a higher risk of suicide attempts, hospitalizations, mood episodes and days ill $[1,2,6]$. 
The presence of SUD also increases the risk of liver disease, particularly chronic hepatitis $\mathrm{C}$ virus $(\mathrm{HCV})$ infection and alcohol-related liver diseases. HCV infection is the most common blood-borne viral infection in the US; approximately $1.8 \%$ of the general population is chronically infected [7]. Despite the lower numbers of HCV infections among activeduty personnel and reservists, the prevalence of $\mathrm{HCV}$ infection in veterans using Veterans Affairs (VA) facilities has repeatedly been shown to be higher than the general population. Dominitz et al. [8] found that an estimated 5.4\% of veterans who access medical care through the VA are infected with $\mathrm{HCV}$, three times the prevalence in the general population. Injection drug use continues to represent the primary mode of transmission for HCV. It is estimated that approximately $60 \%$ of the 4 million existing cases of $\mathrm{HCV}$ infection and two thirds of the 35,000 new cases of HCV infection in the US each year result directly from injection drug use behavior $[9,10]$. Various cross-sectional seroprevalence studies suggest that $60 \%$ to $90 \%$ of injection drug users are $\mathrm{HCV}$-antibody positive [11]. However, relative to the general population, the prevalence of $\mathrm{HCV}$ infection is also high among non-injection drug users. One study of 700 noninjection drug users (heroin, cocaine or crack) showed that the prevalence of $\mathrm{HCV}$ infection ranged from $5 \%$ to $29 \%$, depending on age, gender, study location and drugs used [12].

An initial study of veterans accessing Veterans Integrated Services Network (VISN) 20 facilities in Alaska, Idaho, Oregon and Washington examined the prevalence of HCV infection in veterans with schizophrenia and schizoaffective disorder. Over 293,000 veterans who used VISN 20 facilities between 1998 and 2003 were divided into four groups: (1) patients with schizophrenia or schizoaffective disorder but no SUD (4,192 veterans); (2) patients with an SUD but no schizophrenia or schizoaffective disorder (39,922 veterans); (3) patients with a history of both schizophrenia or schizoaffective disorder and SUD (4,644 veterans); and (4) patients with no history of schizophrenia or schizoaffective disorder or SUD (244,597 veterans). Approximately 47.5\% of the veterans with schizophrenia or schizoaffective disorder but no SUD were tested for HCV; of these, 9.9\% had confirmed $\mathrm{HCV}$ infection. Among the veterans with only an SUD, 63.0\% were tested for $\mathrm{HCV}$ and $27.0 \%$ of these had confirmed HCV infection. Among the veterans with schizophrenia or schizoaffective disorder and an SUD, $72.3 \%$ were tested for $\mathrm{HCV}$, of whom $31.1 \%$ had confirmed $\mathrm{HCV}$ infection. This compared with a testing rate of $30.1 \%$ and an infection rate of HCV of 5.3\% in veterans with neither SUD nor schizophrenia or schizoaffective disorder [13].

In a second study, using the same VISN 20 electronic database but including veterans seen between 1998 and 2004, we examined the prevalence of HCV infection in veterans who had bipolar disorder with comorbid SUD (4700) and without comorbid SUD (5026). Again, findings showed that veterans with bipolar disorder were at higher risk for $\mathrm{HCV}$ infection than those without bipolar disorder. Among those tested who had bipolar disorder with SUD (81.7\%), 29.6\% had confirmed
HCV infection; among those tested who had bipolar disorder but no comorbid SUD (59.8\%), 7.1\% had confirmed HCV infection [14]. These two studies suggest that patients with bipolar disorder or schizophrenia are at high risk for $\mathrm{HCV}$ infection, particularly if they have comorbid SUDs.

The current study expanded these initial findings by examining the prevalence of three liver diseases [HCV infection, nonalcoholic fatty liver disease (NAFLD) and alcohol-related cirrhosis] in veterans with bipolar disorder or schizophrenia or schizoaffective disorder, while controlling for other possible factors associated with SMI such as demographic variables, physical disease, and SUD. Adjusted odds ratios (ORs) are presented in a series of logistic regression models. No adjustment was made for multiplicity.

\section{Methods}

\subsection{Study design}

A retrospective analysis of data included in the VISN 20 Consumer Health Information and Performance Set Data Warehouse examined data on all patients seen between 2001 and 2006 in VISN 20 facilities and clinics. This study was approved by the Portland VA Medical Center Institutional Review Board, and all principles outlined in the Declaration of Helsinki were followed. Patient data were examined for presence of at least two ambulatory encounters or one inpatient hospital encounter with the diagnosis of schizophrenia or bipolar disorder, based on International Classification of Diseases, 9th Revision, Clinical Modification (ICD-9-CM) codes, during the period from January 1, 2001, to October 31, 2006. The study sample was divided into two groups: (1) those with schizophrenia or schizoaffective disorder and (2) those with bipolar disorder. For each veteran with schizophrenia or bipolar disorder, an individual without a psychiatric diagnosis was randomly selected from the database creating four independent groups: (1) schizophrenia patients, (2) no schizophrenia controls, (3) bipolar patients and (4) non-bipolar controls. These four groups were then analyzed for psychiatric, substance abuse and health-related predictors related to the development of liver diseases.

\subsection{Data analysis}

The prevalence of liver disease-related ICD-9-CM codes was compared among groups after taking into account the differences in age gender, and whether the patient died during the observation period. In order to investigate the effects of risk factors on liver disease, a forward-entry logistic regression model was calculated with the dependent variables of overall liver disease and separately for three specific liver diseases (chronic HCV infection, alcoholrelated cirrhosis and NAFLD). In Step 1, age, gender, and death were entered as covariates in one block. In Step 2, diabetes, obesity, hypertriglyceridemia, hypertension, current and past drug use diagnosis, alcohol use and current human immunodeficiency virus (HIV) infection were 
Table 1

Percentages and odd ratios of the risk for liver disease in veterans with and without schizophrenia and bipolar disorder

\begin{tabular}{|c|c|c|c|c|c|}
\hline Disease & $\begin{array}{l}\text { With SZ } \\
(n=6521)\end{array}$ & $\begin{array}{l}\text { Without SZ } \\
(n=6521)\end{array}$ & OR & $\begin{array}{l}\text { Lower } \\
95 \% \text { CI }\end{array}$ & $\begin{array}{l}\text { Upper } \\
95 \% \text { CI }\end{array}$ \\
\hline $\begin{array}{l}\text { Overall liver } \\
\text { disease }\end{array}$ & 22.4 & 3.2 & 8.7 & 7.5 & 10.1 \\
\hline $\begin{array}{l}\mathrm{HCV} \\
\text { infection }\end{array}$ & 16.5 & 1.9 & 10.2 & 8.4 & 12.3 \\
\hline $\begin{array}{l}\text { Alcoholic } \\
\text { cirrhosis }\end{array}$ & 1.6 & 0.4 & 4.1 & 2.6 & 6.3 \\
\hline \multirow[t]{2}{*}{ NAFLD } & 1.5 & 0.2 & 7.5 & 4.2 & 13.3 \\
\hline & $\begin{array}{l}\text { With BP } \\
(n=5319)\end{array}$ & $\begin{array}{l}\text { Without BP } \\
(n=5319)\end{array}$ & OR & $\begin{array}{l}\text { Lower } \\
95 \% \text { CI }\end{array}$ & $\begin{array}{l}\text { Upper } \\
95 \% \text { CI }\end{array}$ \\
\hline $\begin{array}{l}\text { Overall liver } \\
\text { disease }\end{array}$ & 21.5 & 3.5 & 7.6 & 6.4 & 8.8 \\
\hline $\begin{array}{l}\mathrm{HCV} \\
\quad \text { infection }\end{array}$ & 15.5 & 2.1 & 8.6 & 7.0 & 10.5 \\
\hline $\begin{array}{l}\text { Alcoholic } \\
\text { cirrhosis }\end{array}$ & 1.6 & 0.4 & 3.8 & 2.3 & 6.1 \\
\hline NAFLD & 1.1 & 0.3 & 3.3 & 1.9 & 5.6 \\
\hline
\end{tabular}

BP, bipolar disease; SZ, schizophrenia.

All ORs are significant at $P<.05$.

entered. In the last step, bipolar disorder or schizophrenia was entered to determine the adjusted odds ratios of the presence of liver disease in patients with schizophrenia or bipolar disorder. Structured Query Language (SQL v. 2008) was used for all data management and SPSS (v.17) was used to analyze these data. Interactions among the predictors were not specified in this model because all of the predictors were dichotomous variables. Thus, there was not sufficient variance to include both main effects and interactions based on two non-normally distributed binary variables.

\section{Results}

\subsection{Study sample}

We identified 6521 patients with schizophrenia and 5319 patients with bipolar disorder. The majority of patients were male (schizophrenia sample, 93.8\%; bipolar disorder sample, $90.2 \%$ ). Approximately $12 \%$ died during the observation period (schizophrenia, 11.9\%; bipolar disorder, 12.2\%). The average age of patients in the groups with SMI was lower (schizophrenia, 57.2 years; bipolar disorder, 54.3 years) than in the control groups (schizophrenia control group, 62.4 years; bipolar disorder control group, 62.6 years). This difference may be due in part to the fact that patients with SMI are likely to seek treatment earlier because of mental health concerns. Rather than match the controls for age, which would distort the natural characteristics of this sample, we chose to statistically control for the effects of age by entering it first in the regression equations. Veterans with an alcohol use disorder composed $50.2 \%$ of the schizophrenic sample and $5.4 \%$ of controls; $51.1 \%$ of the bipolar sample and $5.2 \%$ of their controls. The percentage of veterans with a drug use disorder diagnosis was $65.0 \%$ for schizophrenic veterans and $11.6 \%$ of their controls; $60.3 \%$ for bipolar veterans and $11.7 \%$ of their controls.

\subsection{Veterans with schizophrenia}

Table 1 presents percentages and unadjusted odds ratios of the risk of developing three specific liver diseases and the rates of overall liver diseases in veterans with schizophrenia or schizoaffective disorder. The ORs for the 6521 veterans with schizophrenia show a higher prevalence of overall liver disease (22.4\%) than the set of veterans without SMI (3.2\%). The OR was 8.73 , indicating the schizophrenia diagnosis increased the likelihood of having a liver disease eightfold. The prevalence of HCV infection was also higher for veterans with schizophrenia, alcohol-related cirrhosis, and NAFLD. All ORs were significant at the $P<.001$ level.

\subsection{Overall liver disease}

A logistic regression model (Table 2) demonstrates that veterans with liver diseases were more likely to be male and younger (probably because the SMI group was younger) and were more likely to have died during the observation period. The significant risk factors for liver disease were diabetes

Table 2

Logistic regression models for patients with schizophrenia compared with controls

\begin{tabular}{|c|c|c|c|c|c|c|c|c|c|c|c|c|}
\hline \multirow[t]{2}{*}{ Variable } & \multicolumn{3}{|c|}{$\begin{array}{l}\text { Overall liver disease } \\
(N=13,042)\end{array}$} & \multicolumn{3}{|c|}{ HCV infection $(N=13,042)$} & \multicolumn{3}{|c|}{$\begin{array}{l}\text { Alcohol-related cirrhosis } \\
(N=13,042)\end{array}$} & \multicolumn{3}{|c|}{ NAFLD $(N=13,042)$} \\
\hline & Adj OR & S.E. & $P$ value & Adj OR & S.E. & $P$ value & Adj OR & S.E. & $P$ value & Adj OR & S.E. & $P$ value \\
\hline Gender & 0.616 & 0.148 & .001 & 0.450 & 0.195 & $<.001$ & 0.230 & 1.012 & .015 & 0.960 & 0.429 & .924 \\
\hline Age & 0.981 & 0.003 & $<.001$ & 0.979 & 0.003 & $<.001$ & 0.982 & 0.009 & .040 & 1.000 & 0.009 & .664 \\
\hline Died & 1.625 & 0.085 & $<.001$ & 1.163 & 0.100 & .130 & 5.334 & 0.197 & $<.001$ & 1.105 & 0.277 & .719 \\
\hline Diabetes & 1.289 & 0.076 & .001 & 1.377 & 0.089 & $<.001$ & 2.299 & 0.217 & $<.001$ & 1.414 & 0.229 & .130 \\
\hline Obesity & 1.002 & 0.072 & .975 & 0.710 & 0.085 & $<.001$ & 0.561 & 0.250 & .021 & 1.453 & 0.222 & .092 \\
\hline Hypertriglyceridemia & 0.986 & 0.153 & .926 & 0.488 & 0.212 & .001 & 0.313 & 0.733 & .113 & 2.076 & 0.351 & .038 \\
\hline Hypertension & 1.272 & 0.065 & $<.001$ & 1.014 & 0.074 & .085 & 0.988 & 0.205 & .953 & 1.359 & 0.225 & .172 \\
\hline HIV & 3.543 & 0.282 & $<.001$ & 3.775 & 0.284 & $<.001$ & 0.988 & 0.635 & .319 & 2.313 & 0.733 & .252 \\
\hline SUD & 2.279 & 0.087 & $<.001$ & 2.993 & 0.107 & $<.001$ & 1.198 & 0.333 & .588 & 1.181 & 0.271 & .538 \\
\hline Alcohol use disorder & 3.049 & 0.076 & $<.001$ & 2.915 & 0.088 & $<.001$ & 38.450 & 0.435 & $<.001$ & 1.345 & 0.252 & .239 \\
\hline $\mathrm{SZ}$ & 2.736 & 0.089 & $<.001$ & 3.118 & 0.111 & .000 & 0.525 & 0.254 & .011 & 4.932 & $\mathbf{0 . 3 3 0}$ & $<.001$ \\
\hline
\end{tabular}

Adj, adjusted. 
$(\mathrm{OR}=1.29)$, hypertension $(\mathrm{OR}=1.27)$, $\mathrm{HIV}(\mathrm{OR}=3.54)$, SUD $(\mathrm{OR}=2.28)$ and alcohol use disorder $(\mathrm{OR}=3.05)$. The adjusted odds ratio for the presence of schizophrenia when controlling for the other covariates showed that the risk of having overall liver disease increased by almost threefold for those with schizophrenia $(\mathrm{OR}=2.74)$. All ORs were significant at $P<.005$.

\subsection{Hepatitis $C$ virus infection}

Another model also presented in Table 2 examined the same set of risk factors for $\mathrm{HCV}$ infection in patients with and without schizophrenia. Results for HCV infection were similar to those for overall liver disease, as veterans with $\mathrm{HCV}$ were more likely to be male and younger. Additional significant risk factors were diabetes $(\mathrm{OR}=1.37)$, HIV $(\mathrm{OR}=3.77)$, SUD $(\mathrm{OR}=2.90)$ and alcohol use disorder $(\mathrm{OR}=2.92)$. Obesity $(\mathrm{OR}=0.71)$ and hypertriglyceridemia $(\mathrm{OR}=0.49)$ were lower for those with $\mathrm{HCV}$ were less likely to have a diagnosis of obesity or hypertriglyceridemia. The presence of schizophrenia elevated the risk of having $\mathrm{HCV}$ infection threefold after controlling for the other health effects $(\mathrm{OR}=3.11)$. All ORs were significant at $P<.001$.

\subsection{Alcohol-related cirrhosis}

The logistic regression model in Table 2 indicated that people with alcohol-related cirrhosis were more likely to be male and to have died during the observation period. Other significant risk factors were diabetes $(\mathrm{OR}=2.29)$ and alcohol use disorder $(\mathrm{OR}=38.45)$. Protective factors included obesity $(\mathrm{OR}=0.56)$ and the presence of schizophrenia $(\mathrm{OR}=0.53)$. All ORs were significant at $P<.05$.

\subsection{Nonalcoholic fatty liver disease}

The model in Table 2 examined risk factors for NAFLD in patients with and without schizophrenia. The significant risk factors were hypertriglyceridemia $(\mathrm{OR}=2.07)$ and presence of schizophrenia $(\mathrm{OR}=4.93)$. All ORs were significant at $P<.05$.

\subsection{Veterans with bipolar disorder}

Veterans with bipolar disorder $(n=5319)$ also had a higher prevalence of overall liver disease (21.5\%) than a matched set of veterans without bipolar disorder $(3.5 \%$; OR $=7.58)$ (Table 1$)$. The prevalence of HCV infection $(15.5 \%$ versus $2.1 \%$; $\mathrm{OR}=8.60)$ and alcohol-related cirrhosis $(1.6 \%$ versus $0.4 \%$; $\mathrm{OR}=3.82$ ) were higher for veterans with bipolar disorder as well. All ORs were significant at $P<.05$ and are presented in Table 1.

\subsection{Any liver disease}

A model for patients with bipolar disorder with the dependent variable of any liver disease indicated that patients were more likely to be male, to be younger and to have died during the observation period. The risk factors for the presence of liver disease were diabetes $(\mathrm{OR}=1.40)$, HIV infection $(\mathrm{OR}=3.66)$, SUD $(\mathrm{OR}=2.68)$ and alcohol use disorder $(\mathrm{OR}=3.22)$. Bipolar disorder elevated the risk of liver disease as well $(\mathrm{OR}=2.27)$. Table 3 presents the logistic regression models for patients with bipolar disorder compared with controls. All ORs were significant at $P<.005$.

\subsection{Hepatitis $C$ virus infection}

Veterans with HCV infection were more likely to be male, to be younger, and to have died during the observation period. Table 3 shows that the risk factors for contracting $\mathrm{HCV}$ infection were hypertriglyceridemia $(\mathrm{OR}=1.59)$, HIV infection $(\mathrm{OR}=2.88)$, SUD $(\mathrm{OR}=3.46)$ and alcohol use disorder $(\mathrm{OR}=3.26)$. Similar to the overall liver disease results, bipolar disorder elevated risk of $\mathrm{HCV}$ infection $(\mathrm{OR}=2.31)$. All ORs were significant at $P<.005$.

\subsection{Alcohol-related cirrhosis}

A logistic regression examined a set of risk factors for alcohol-related cirrhosis for patients with and without bipolar disorder. Patients with alcohol-related cirrhosis

Table 3

Logistic regression models for patients with bipolar disorder compared with controls

\begin{tabular}{|c|c|c|c|c|c|c|c|c|c|c|c|c|}
\hline \multirow[t]{2}{*}{ Variable } & \multicolumn{3}{|c|}{$\begin{array}{l}\text { Overall liver disease } \\
(N=10,638)\end{array}$} & \multicolumn{3}{|c|}{ HCV infection $(N=10,638)$} & \multicolumn{3}{|c|}{$\begin{array}{l}\text { Alcohol-related cirrhosis } \\
(N=10,638)\end{array}$} & \multicolumn{3}{|c|}{ NAFLD $(N=10,638)$} \\
\hline & Adj OR & S.E. & $P$ value & Adj OR & S.E. & $P$ value & Adj OR & S.E. & $P$ value & Adj OR & S.E. & $P$ value \\
\hline Gender & 0.698 & 0.122 & .003 & 0.546 & 0.153 & $<.001$ & 0.445 & 0.598 & .176 & 1.716 & 0.336 & .107 \\
\hline Age & 0.988 & 0.003 & $<.001$ & 0.989 & 0.004 & .001 & 0.998 & 0.010 & .833 & 0.994 & 0.010 & .574 \\
\hline Died & 1.954 & 0.106 & $<.001$ & 1.594 & 0.121 & $<.001$ & 5.081 & 0.227 & .000 & 1.600 & 0.347 & .176 \\
\hline Diabetes & 1.404 & 0.088 & $<.001$ & 1.185 & 0.104 & .102 & 2.393 & 0.235 & .000 & 2.498 & 0.269 & .001 \\
\hline Obesity & 1.108 & 0.081 & .205 & 0.960 & 0.094 & .667 & 0.889 & 0.261 & .651 & 0.881 & 0.283 & .654 \\
\hline Hypertriglyceridemia & 0.797 & 0.205 & .268 & 0.494 & 0.283 & .013 & 0.645 & 0.737 & .553 & 1.944 & 0.481 & .167 \\
\hline Hypertension & 1.207 & 0.073 & .010 & 1.047 & 0.083 & .580 & 0.982 & 0.224 & .935 & 1.467 & 0.271 & .157 \\
\hline HIV & 3.658 & 0.274 & $<.001$ & 2.888 & 0.288 & $<.001$ & 2.795 & 0.627 & .101 & $\mathrm{NA}^{\mathrm{a}}$ & $\mathrm{NA}^{\mathrm{a}}$ & $\mathrm{NA}^{\mathrm{a}}$ \\
\hline SUD & 2.682 & 0.099 & $<.001$ & 3.463 & 0.126 & $<.001$ & 0.981 & 0.338 & .954 & 1.145 & 0.317 & .670 \\
\hline Alcohol use disorder & 3.216 & 0.092 & $<.001$ & 3.263 & 0.111 & $<.001$ & 36.687 & 0.454 & .000 & 0.985 & 0.322 & .964 \\
\hline $\mathrm{BP}$ & 2.269 & 0.098 & $<.001$ & 2.312 & 0.122 & $<.001$ & 0.616 & 0.290 & .095 & 2.565 & 0.316 & .003 \\
\hline
\end{tabular}

N.A., not applicable.

${ }^{a}$ HIV was removed from this model because there were no cases of NAFLD in participants with HIV. 
were more likely to have died during the observation period. Results indicated that for patients with alcohol-related cirrhosis, significant risk factors were diabetes $(\mathrm{OR}=2.39)$ and alcohol use disorder $(\mathrm{OR}=36.68)$. Bipolar disorder was not significant $(\mathrm{OR}=0.616 ; P=.095)$.

\subsection{Nonalcoholic fatty liver disease}

A model examined risk factors for NAFLD for patients with and without bipolar disorder, demonstrating that the risk factors were diabetes $(\mathrm{OR}=2.50 ; P<.001)$ and the presence of bipolar disorder $(\mathrm{OR}=2.57 ; P<.003)$. HIV infection was removed from this model because there were no cases of NAFLD in patients with HIV infection.

\section{Discussion}

This study demonstrated that the presence of SMI was a significant risk factor for the diagnosis of liver disease, including HCV infection and NAFLD. Even when other conditions were controlled, the prevalence of liver disease was approximately $2-2.5$ times higher in veterans with SMI. However, this effect was associational because the study design did not assess causation. These results also indicated that veterans with liver disease were significantly more likely to have comorbid conditions. Earlier reports of the relationship between SMI and liver disease [13] did not account for other competing causes such as health conditions and alcohol and drug use. In this manuscript, we are able to conclude that this relationship is maintained even with significant covariates.

\subsection{Hepatitis $C$ virus infection}

People with HCV were more likely to be younger, indicating they have earlier contact with medical providers because of early identification and mandatory testing and notification efforts. They were also more likely to be male as this was a study of veterans. Veterans with HCV and bipolar disorder were more likely to die during the observation period but this was not observed for veterans with schizophrenia. HIV infection and drug use disorders (SUD) were uniquely significant covariates for both bipolar and schizophrenic veterans with $\mathrm{HCV}$ likely due to the common set of risk factors (i.e., needle sharing) for transmission of both bloodborne diseases. Alcohol use disorders were also higher for both schizophrenic and bipolar veterans with HCV likely due to the comorbidity of alcohol and drug use.

A paradoxical finding for the schizophrenic sample showed that obesity and hypertriglyceridemia were less likely among HCV patients. The simple unadjusted odds ratio between obesity and HCV (OR: 1.37; 95\% CI 1.191.59) was greater than 1.00 , indicating that when observed without covariates, obesity was more likely to be present in veterans with $\mathrm{HCV}$. The unadjusted odds ratio between hypertriglyceridemia and HCV was OR: 1.15 (95\% CI .691.51). Thus, a previously not significant relationship became a "protective factor." These two protective effects in the model are likely due to statistical suppression and not evidence for a true protective factor.

\subsection{Alcohol-related cirrhosis}

The simple ORs among SMIs and alcohol-related cirrhosis were significant risk factors (see Table 1). However, when the covariates were added into the model the presence of SMI did not predict an increase in alcoholrelated cirrhosis except for a weak effect $P<.011$ in the schizophrenia sample. This effect was likely due to the large effect that alcohol has on the development of cirrhosis. Diabetes and obesity were strongly predictive of the presence of cirrhosis as well indicating that lifestyle choices contribute to the development of cirrhosis to a large degree. Thus, the effect of SMI on cirrhosis was overwhelmed by inclusion of lifestyle factors such as diet, exercise and alcohol use. Statistical suppression changed the valence of the odds ratio for presence of schizophrenia from a risk factor to a protective factor.

\subsection{Nonalcoholic fatty liver disease}

The patients with NAFLD had fewer covariates that were significant predictors of their disease. However, both bipolar and schizophrenia were both positive predictors of NAFLD. Diabetes was the only predictor for the bipolar sample that was significant. The exact cause of NAFLD is still unknown; however, both obesity and diabetes play a strong role in the development of this disease. The exact reasons and mechanisms by which the disease progresses from one stage to the next are not known.

\section{Conclusions}

Given the high incidence of SUD comorbidities, veterans with bipolar disorder or schizophrenia are at increased risk for $\mathrm{HCV}$ infection and alcohol-related cirrhosis. Hepatitis A and $B$ virus infections were not examined in this study because of very few reported cases in the database. Although the presence of acute and chronic hepatitis A and hepatitis B virus infection may also be higher in patients with SMI, future studies will need to determine whether this is a reportable trend. Alcohol use accelerates the liver damage caused by $\mathrm{HCV}$. Efforts aimed at encouraging lifestyle choices that reduce alcohol use are important in order to minimize their impact on liver health in veterans with liver disease. Such interventions are vitally important to people with SMI and liver disease. An important strategy to consider in patients with liver disease is screening for alcohol problems using short instruments such as the three-item Alcohol Use Disorders Identification Test-Consumption module [15] with positive results followed by brief motivational enhancement therapy interventions. Patients with SMI and liver disease should be given priority for such interventions, as well as referrals to substance abuse treatment services, to 
reduce the progression toward cirrhosis. Another consideration for veterans with bipolar disorder and schizophrenia is choice of medication and the effect of medications on liver function. Research shows that liver disease testing and education can alter behavior and improve treatment for substance abuse. Rifai et al. [16] initiated routine or universal $\mathrm{HCV}$ screening in a substance abuse treatment community clinic where $23 \%$ of veterans were $\mathrm{HCV}$ positive. Veterans who were $\mathrm{HCV}$ positive were more likely to remain abstinent after treatment and were more likely to stay in treatment than those who were $\mathrm{HCV}$ negative.

Factors such as homelessness, use of atypical antipsychotic medication or inpatient hospital admissions were not able to be measured in this study. Limitations such as these are common in large retrospective studies. Additional research would be helpful in explicating the effects of some of these additional factors. More complex modeling with interactions is also difficult with data that are binary, and thus, some variation was not able to be modeled.

Willenbring [17] and others [18-23] suggest that integrated health care models are an important aspect of the treatment of this population. $\mathrm{HCV}$-positive patients are more likely to have psychiatric, cognitive and SUD comorbidities; coinfection with HIV; as well as additional social problems, such as lack of housing, transportation, and income. These problems present serious barriers to treatment and management of care. Treatment that is fragmented in separate locations or through inadequate communication within a system only serves to ensure poor adherence, treatment dropouts and poorer outcomes. The integration of substance abuse treatment services, mental health services, social services and hepatology and internal medicine specialists can greatly improve communication and coordinate care. Fully integrated multidisciplinary teams have been used to improve disease management for many other disease models and can be done for this population as well. Careful monitoring of the approach and quality control procedures will maximize chances that a model such as this would work to provide the best services for this medically and psychologically complex population.

\section{Acknowledgments}

The authors would like to thank Matthew Grzywacz, Ph.D., and ApotheCom (funded by Ortho-McNeil Janssen Scientific Affairs) for providing technical and editorial assistance with this manuscript.

\section{References}

[1] Regier DA, Farmer ME, Rae DS, et al. Comorbidity of mental disorders with alcohol and other drug abuse: results from the Epidemiologic Catchment Area (ECA) Study. JAMA 1990;264:2511-8.

[2] Kessler RC McGonagle KA, Zhao S, et al. Lifetime and 12-month prevalence of DSM-III-R psychiatric disorders in the United States: results from the National Comorbidity Survey. Arch Gen Psychiatry 1994;51:8-19.

[3] Keck PE, McElroy SL, Strakowski SM, et al. 12-month outcome of patients with bipolar disorder following hospitalization for a manic or mixed episode. Am J Psychiatry 1998;155:646-52.

[4] Rosenberg SD, Goodman LA, Osher FC, et al. Prevalence of HIV, hepatitis $\mathrm{B}$, and hepatitis $\mathrm{C}$ in people with severe mental illness. Am J Public Health 2001;91:31-7.

[5] Osher FC, Goldberg RW, McNary SW, et al. Substance abuse and the transmission of hepatitis $\mathrm{C}$ among persons with severe mental illness. Psychiatr Serv 2003;54:842-7.

[6] Winokur G, Coryell W, Akiskal HS, et al. Alcoholism in manicdepressive (bipolar) illness: familial illness, course of illness, and the primary-secondary distinction. Am J Psychiatry 1995;152:365-72.

[7] Alter MJ, Kruszon-Moran D, Nainan OV, et al. The prevalence of hepatitis C virus infection in the United States, 1988 through 1994. N Engl J Med 1999;341:556-62.

[8] Dominitz JA, Boyko EJ, Koepsell TD, et al. Elevated prevalence of hepatitis $\mathrm{C}$ infection in users of United States veterans medical centers. Hepatology 2005;41(1):88-96.

[9] Centers for Disease Control and Prevention. Department of Health and Human Services: Vital and Health Statistics. Series 5, No. 10. Washington, DC: Centers for Disease Control; 1999.

[10] Patrick DM, Buxton JA, Bigham M, et al: Public health and hepatitis C. Canadian Journal of Public Health 91(Suppl 1):S18-21, S19-23, 2000.

[11] McCarthy JJ, Flynn N. Hepatitis C in methadone maintenance patients: prevalence and public policy implications. J Addict Disord 2001;20:19-31.

[12] Tortu S, Neaigus A, McMahon J, et al. Hepatitis C among noninjecting drug users: a report. Subst Use Misuse 2001;36:523-34.

[13] Huckans M, Blackwell AD, Harms TA, et al. Hepatitis C disease management patterns in high-risk populations: testing, infection, and treatment rates among patients with schizophrenia, schizoaffective disorder, and SUDs. Psychiatr Serv 2006;57(3):403-6.

[14] Matthews AM, Huckans M, Blackwell AD, et al. Hepatitis C testing and infection rates in bipolar patients with and without co-morbid substance use disorders. Bipolar Disord 2000;10(2):266-70.

[15] Babor TF, Higgins-Biddle JC, Saunders JB, et al. Alcohol Use Disorders Identification Test (AUDIT). 2nd. Geneva, Switzerland: World Health Organization; 2001.

[16] Rifai M, Moles J, Lehman L, et al. Hepatitis C screening and treatment outcomes in patients with substance use/dependence disorders. Psychosomatics 2006;47:112-22.

[17] Willenbring M. Integrating care for patients with infectious, psychiatric, and substance use disorders: concepts and approaches. AIDS 2005;19:S227-37.

[18] Loftis JM, Hauser P. Prevalence of psychiatric and substance use disorder comorbidities in patients with hepatitis C. Dir Psychiatry 2008;28(4):211-26.

[19] Loftis JM, Hauser P. Treating hepatitis C in patients with comorbid psychiatric and substance use disorders. Dir Psychiatry 2008;28 (4):227-43.

[20] Sylvestre DL, Loftis JM, Hauser P, et al. Co-occurring hepatitis C, substance use, and psychiatric illness: treatment issues and developing integrated models of care. J Urban Health 2004;81(4):719-34.

[21] Loftis JM, Hauser P. Hepatitis C in patients with psychiatric disease and substance abuse: screening strategies and co-management models of care. Curr Hepat Rep 2003;2(3):93-100.

[22] Fireman M, Indest D, Blackwell AD, et al. Addressing tri-morbidity (hepatitis C, psychiatric disorders, and substance use): the importance of routine mental health screening as a component of comanagement model of care. Clin Infect Dis 2005;40(15):S286-91.

[23] Loftis JM, Matthews AM, Hauser P. Psychiatric and substance use disorders in individuals with hepatitis C: epidemiology and management. Drugs 2006;66(2):155-74. 